\title{
ОБЪЕКТЫ УНИФИКАЦИИ НОРМ ЗАКОНОДАТЕЛЬСТВА О ПРАВООХРАНИТЕЛЬНОЙ СЛУЖБЕ
}

$\mathrm{O}$ тсутствие закона о правоохранительной службе в системе служебного права России негативно сказывается на его развитии. Представляется неудачным эксперимент законодателя компенсировать отсутствие данного закона отдельными актами как законодательного, так и подзаконного уровня. Такой вариант нормативного регулирования не решает задачу системного реформирования правоохранительной службы, обеспечивающего единство ее правовых и организационных основ. Обилие норм, находящихся в разных источниках, необходимость их соотносить усложняет правоприменительную практику и порождает ошибки, снижающие эффективность реализации правоохранительных функций сотрудниками правоохранительных органов.

Усложняет правоприменение и частое редактирование вновь принятых нормативных актов (например, Федеральный закон от 7 февраля 2011 г. «О полиции» ${ }^{1}$ (далее - Закон о полиции) редактировался 12 раз, что демонстрирует непоследовательность позиции законодателя и неопределенность его представле-

1 С3 РФ. 14.02.2011. - № 7. - Ст. 900. ния о модели реформирования правоохранительной службы. Достаточно напомнить, насколько отличается формулирование принципов правоохранительной службы в разных федеральных законах не только по содержанию, но и по юридической технике. Таким образом, принятие Закона о полиции, Федерального закона от 30.11.2011 № 342-Ф3 «О службе в органах внутренних дел Российской Федерации и внесении изменений в отдельные законодательные акты Российской Федерации» (далее - Закон о службе в органах внутренних дел), редактирование ранее принятых федеральных законов, регулирующих службу в различных правоохранительных органах, не снижает актуальность задачи унификации законодательства о правоохранительной службе, результатом которой может стать закрепление унифицированных норм в едином федеральном законе о правоохранительной службе.

Решение данной задачи должно быть основано на классификации правоохранительных органов с целью определения масштаба унификации. С учетом сферы

2 СЗ РФ. 05.12.2011. - № 49 (ч. 1). - Ст. 7020. 
действия Закона о службе в органах внутренних дел правоохранительные органы условно можно разделить на три группы.

Первая группа - не попадающие в сферу регулирования данного Закона государственные органы с особым назначением и статусом, которые не являются органами исполнительной власти. Это Следственный комитет РФ и прокуратура РФ, правоохранительная служба в этих органах регулируется отдельными федеральными законами. В силу специфики деятельности данных органов сохранение автономного регулирования правоохранительной службы сотрудников Следственного комитета и прокуратуры РФ представляется оправданным.

Вторая группа - это правоохранительные органы, реализующие функции исполнительной власти и подпадающие под действие Закона о службе в органах внутренних дел. К ним относятся Министерство внутренних дел, Федеральная служба исполнения наказаний, Федеральная миграционная служба, Государственная фельдъегерская служба, Государственная противопожарная служба МЧС РФ (как структурная единица МЧС РФ).

Третья группа - правоохранительные органы, являющиеся органами исполнительной власти, правоохранительная служба в которых регулируется иными нормативными актами, на них Закон о службе в органах внутренних дел также не распространяется. Сюда можно отнести Федеральную таможенную службу и Федеральную службу по контролю за оборотом наркотиков.

Дальнейшая унификация законодательства о правоохранительной службе должна осуществляться в целях выравнивания статуса сотрудников правоохранительных органов второй и третьей группы и порядка прохождения ими правоохранительной службы.

Общими для этапа поступления на службу в правоохранительные органы являются установление ограничений, испытательного срока и заключение служебного контакта.

Так, Закон о полиции содержит закрытый перечень случаев, которые исключают службу в полиции ${ }^{3}$. Данные ограничения распространяются на всех лиц, подпадающих под действие Закона о службе в органах внутренних дел. Перечень таких ограничений шире, чем, например, в Федеральном законе от 21.07.1997 № 114-Ф3 «О службе в таможенных органах Российской Федерации» (далее - Закон о службе в таможенных органах $)^{4}$, и очень близок к ограничениям,

\footnotetext{
Статья 29 Закона о полиции.

4 Статья 7 Закона о службе в таможенных органах // СЗ РФ. 28.07.1997. - № 30. - Ст. 3586.
}

установленным для службы в органах Федеральной службы по контролю за оборотом наркотиков 5 .

Испытательный срок для сотрудников органов внутренних дел и лиц, подпадающих под действие Закона о службе в органах внутренних дел ${ }^{6}$, устанавливается на срок не менее 3 месяцев, по итогам деятельности в качестве стажера выносится рекомендация о признании его выдержавшим или не выдержавшим испытание. В сфере таможенной службы устанавливается максимальный срок испытания - до 6 месяцев, срок может быть сокращен по решению начальника таможенного органа, назначившего указанного гражданина на должность ${ }^{7}$. Для гражданина, впервые поступающего на службу в органы наркоконтроля, испытание может устанавливаться продолжительностью от 3 до 6 месяцев, в зависимости от уровня его профессиональной подготовки и должности, на которую он назначается 8 .

Заключение контракта как юридическая процедура также не имеет существенных отличий в правоохранительных органах.

Отношения в сфере службы в органах внутренних дел закрепляются в контракте о прохождении службы в органах внутренних дел. Контракт может заключаться на неопределенный срок или на определенный срок. Контракт, заключенный на неопределенный срок, действует до достижения сотрудником предельного возраста пребывания на службе в органах внутренних дел, за исключением случаев, установленных Законом о службе в органах внутренних дел РФ. Контракт на определенный срок (срочный контракт) заключается только в случаях, определенных данным Законом. Таких случаев 11, и перечень их является открытым.

Контракт о службе в таможенных органах заключается в письменной форме между гражданином и соответствующим таможенным органом в лице его начальника на срок один год, три года, пять или десять лет, а также до достижения гражданином предельного возраста пребывания на службе в таможенных органах ${ }^{10}$

\footnotetext{
Пункт 16 Указ Президента РФ от 05.06.2003 № 613 «О правоохранительной службе в органах по контролю за оборотом наркотических средств и психотропных веществ» (далее - Указ о службе в органах наркоконтроля) // СЗ РФ. 09.06.2003. - № 23. - Ст. 2197.

6 Статья 24 Закона о службе в органах внутренних дел.

7 Статья 9 Закона о службе в таможенных органах.

8 Пункт 23 Указа о службе в органах наркоконтроля.

9 Пункт 5 ст. 22 Закона о службе в органах внутренних дел.

10 Статья 10 Закона о службе в таможенных органах.
} 
Контракт с сотрудником органов наркоконтроля заключается в письменной форме сроком на один год, три года, пять лет либо на период отсутствия сотрудника, находящегося в отпуске по уходу за ребенком; до достижения им предельного возраста пребывания на службе в органах наркоконтроля в соответствии с законодательством $Р \Phi^{11}$.

В целях унификации этапа поступления на правоохранительную службу в органы исполнительной власти целесообразно установить общие ограничения, аналогичные ограничениям для сотрудников полиции, установить общий срок испытания от 3 до 6 месяцев,, предусмотреть закрытый перечень оснований для заключения срочного служебного контакта и оснований, допускающих поступление на службу без назначения испытательного срока.

Процедуры аттестации в различных правоохранительных органах объединены общей целью (определение уровня профессиональной подготовки сотрудников и их соответствия занимаемой должности), вариантами рекомендаций по ее итогам, технологиям проведения и документационного обеспечения, тождественны или близки по периодичности.

Аттестация сотрудника органов внутренних дел проводится один раз в четыре года. В случае назначения сотрудника на другую должность в органах внутренних дел его аттестация проводится не ранее чем через один год после назначения. Внеочередная аттестация сотрудников органов внутренних дел, претендующих на замещение должностей высшего начальствующего состава, проводится по решению Президента РФ. По результатам аттестации сотрудника органов внутренних дел аттестационная комиссия принимает одну из следующих рекомендаций: сотрудник соответствует замещаемой должности в органах внутренних дел; сотрудник соответствует замещаемой должности в органах внутренних дел и рекомендуется для назначения на вышестоящую должность в органах внутренних дел; сотрудник соответствует замещаемой должности в органах внутренних дел и подлежит включению в кадровый резерв для замещения вышестоящей должности в органах внутренних дел; аттестацию сотрудника следует перенести на срок, не превышающий одного года, для устранения недостатков и упущений в служебной деятельности, указанных в отзыве его непосредственного руководителя (начальника), либо для профессиональной переподготовки или повышения квалификации сотрудника с последующим переводом на иную должность в ор-

11 Пункт 31 Указа о службе в органах наркоконтроля. ганах внутренних дел или без такового; сотрудник не соответствует замещаемой должности в органах внутренних дел и подлежит переводу на нижестоящую должность в органах внутренних дел; сотрудник не соответствует замещаемой должности в органах внутренних дел и подлежит увольнению со службы в органах внутренних дел ${ }^{12}$.

Аттестация сотрудников таможенных органов проводится не чаще одного раза в два года, но не реже одного раза в четыре года. Досрочная аттестация сотрудника таможенного органа может быть проведена по согласованию с начальником вышестоящего таможенного органа ${ }^{13}$.

Аттестация сотрудников органов наркоконтроля проводится с такой же периодичностью. Досрочная аттестация для решения вопроса о соответствии сотрудника занимаемой должности может быть проведена по решению директора ФСКН России (начальника органа наркоконтроля), но не ранее чем через один год со дня назначения сотрудника на должность ${ }^{14}$.

В целях унификации процедур аттестации и повышения требований к сотрудникам правоохранительных органов целесообразно ограничиться такими результатами аттестации, которые признают соответствие сотрудника замещаемой должности с поощрением и (или) включением кадровый резерв для повышения по службе; с признанием соответствия замещаемой должности; с признанием соответствия при условии направления на переподготовку или повышение квалификации; с признанием несоответствия замещаемой должности и последующим переводом на нижестоящую должность, при невозможности перевода - увольнением.

Включение в результаты аттестации такой рекомендации, как перенесение аттестации на срок, не превышающий одного года, для устранения недостатков и упущений в служебной деятельности, указанных в отзыве его непосредственного руководителя (начальника), создает более мягкие условия для сотрудника даже по сравнению с государственной гражданской службой, что никоим образом не способствует развитию самодисциплины, ответственности, активности, развития профессиональных качеств сотрудников правоохранительных органов. Что касается периодичности проведения аттестации, то ее можно установить в пределах не чаще раза в два года и не реже раза в три года, при этом следует сохранить возможность досрочной аттестации. Проведение аттеста-

\footnotetext{
12 Статья 33 Закона о службе в органах внутренних дел.

13 Статья 47 Закона о службе в таможенных органах.

14 Пункты 79-80 Указа о службе в органах наркоконтроля.
} 
ции реже чем раз в три года снижает эффективность и своевременность оценки профессиональных знаний, в том числе знаний об изменениях нормативной базы служебной деятельности, реформировании государственного управления, новых методах правоохранительной деятельности, и т.д.

Регулирование отношений по поводу обеспечения служебной дисциплины в правоохранительных органах включает установление оснований и форм применения дисциплинарных взысканий и поощрений. Представляется крайне неудачной формулировка дисциплинарного проступка сотрудника органов внутренних дел в Законе о службе в органах внутренних дел - «Нарушением служебной дисциплины (дисциплинарным проступком) признается виновное действие (бездействие), выразившееся в нарушении сотрудником органов внутренних дел законодательства РФ, дисциплинарного устава ОВД РФ, должностного регламента (должностной инструкции), правил внутреннего служебного распорядка либо в несоблюдении запретов и ограничений, связанных со службой в ОВД и требований к служебному поведению, либо В неисполнении (ненадлежащем исполнении) обязательств, предусмотренных контрактом, служебных обязанностей, приказов и распоряжений прямых руководителей (начальников) и непосредственного руководителя (начальника) при выполнении основных обязанностей и реализации предоставленных прав» ${ }^{15}$. Такие широкие и не вполне определенные основания («нарушение законодательства РФ») снижают гарантии прав сотрудников правоохранительных органов и расширяют должностные обязанности сотрудников до необозримых пределов, снижают значимость должностного регламента.

Было бы логично в качестве основания для нарушения служебной дисциплины установить действие или бездействие, нарушающее требования, закрепленные в должностном регламенте. При этом должностной регламент должен быть тщательно проработан, в нем должен быть закреплен четкий круг обязанностей и прав сотрудника. В Законе о службе в органах внутренних дел структура должностного регламента не определена, допускается вместо него должностная инструкция. Правовое регулирование должностной регламентации осуществлено в данном Законе формально, нормативное регулирование передано на уровень подзаконных актов, что, по существу, снижает реализацию принципа законности служебной деятельности сотрудников правоохранительных органов.

15 Статья 49 Закона о службе в органах внутренних дел.
Кроме того, необходимо нормативное закрепление грубых нарушений дисциплины как оснований для увольнения. Что касается видов дисциплинарных взысканий, то их перечень в правоохранительных органах, подпадающих под действие Закона о службе в органах внутренних дел, а также таможенных органах и органах наркоконтроля не имеет принципиальных отличий. Для обеспечения эффективности дисциплинарных взысканий вполне достаточно таких видов, которые закреплены в Законе о правоохранительной службе - это замечание; выговор; строгий выговор; предупреждение о неполном служебном соответствии; перевод на нижестоящую должность в органах внутренних дел; увольнение со службы в органах внутренних дел.

Сложностей в унификации перечня видов поощрений не усматривается, они практически сходны во всех правоохранительных органах. Незначительные расхождения форм поощрения (в части наградного оружия (именное, (холодное и (или) огнестрельное), и т.Д., возможности помещения на Доску почета)) не принципиальны.

Нормы, регулирующие правоотношения в сфере организации кадровой работы, также можно рассматривать как объект унификации.

Формирование кадрового состава органов внутренних дел осуществляется на основе следующих принципов, закрепленных в Законе о службе в органах внутренних дел: обязательный профессиональный отбор при равном доступе граждан к службе в органах внутренних дел; совершенствование профессиональных знаний и навыков сотрудников органов внутренних дел; назначение сотрудников органов внутренних дел на должности с учетом уровня их профессиональной подготовки, заслуг в служебной деятельности, личных и деловых качеств; соблюдение последовательности прохождения службы в органах внутренних дел и присвоения специальных званий ${ }^{16}$. Данные принципы достаточно универсальны и не противоречат нормам законодательства о службе в таможенных органах и органах наркоконтроля в части формирования кадрового состава.

Регулирование вопросов подготовки кадров для всех правоохранительных органов, являющихся органами исполнительной власти, основано на перечне методов подготовки кадров - это приобретение основных знаний и навыков в процессе начала служебной деятельности, обучение по образовательным программам различного уровня, дополнительного профессионального образования, повышения квали-

16 Статья 75 Закона о службе в органах внутренних дел. 
фикации и переподготовки. Принципиально необходимым следует считать обязательность физической подготовки на протяжении всей службы во всех правоохранительных органах .

Не для всех правоохранительных органов установлены функциональные основы деятельности кадровых служб. В этой части достаточно удачны нормы Закона о службе в таможенных органах ${ }^{17}:$ кадровая служба таможенных органов обеспечивает реализацию кадровой политики в таможенных органах; осуществляет подбор и расстановку кадров таможенных органов, организует проведение аттестации сотрудников таможенных органов; оформляет решения начальников таможенных органов, связанные с прохождением службы в таможенных органах, ведет личные дела сотрудников таможенных органов, учет численности сотрудников таможенных органов и формирует штатное расписание; организует проведение воспитательных и профилактических мероприятий в таможенных органах, а также деятельность службы психологов таможенных органов; осуществляет иные функции кадрового обеспечения.

Основной функционал кадровых служб в органах внутренних дел в Законе о службе в органах внутренних дел не закреплен. Организация кадровой работы в федеральном органе исполнительной власти в сфере внутренних дел, его территориальных органах, подразделениях осуществляется в порядке, определяемом федеральным органом исполнительной власти в сфере внутренних дел в соответствии со ст. 79 данного Закона.

Таким образом, объектами унификации в сфере организации кадровой работы должны быть принципы формирования кадрового состава, методы подготовки кадров и определение функций кадровых служб. В отношении содержания функций кадровых служб представляется целесообразным унифицировать соответствующие нормы на основе норм Закона о службе в таможенных органах.

Антикоррупционные ограничения и запреты для сотрудников правоохранительных органов уже унифицированы - они тождественны антикоррупционным ограничениям, установленным Федеральным законом «О противодействии коррупции ${ }^{18}$ и ст. 17,18 и 20 Федерального закона от 27 июля 2004 года № 79-Ф3 «О государственной гражданской службе Российской

17 Статья 56 Закона о службе в таможенных органах.

18 Федеральный закон от 25.12.2008 № 273-Ф3 “О противодействии коррупции” // С3 РФ. 29.12.2008. - № 52 (ч. 1). Ст. 6228.
Федерации ${ }^{19}$, за исключением тех, которые могут препятствовать исполнению сотрудником соответствующего органа обязанностей по осуществлению оперативно-розыскной деятельности, данные исключения устанавливаются соответствующим федеральным органом исполнительной власти.

Специфика прохождения правоохранительной службы в правоохранительных органах, являющихся федеральными органами исполнительной власти, обусловлена их особым функциональным предназначением. Поэтому необходимо определение норм, унификация которых нецелесообразна, поскольку она может привести к снижению эффективности реализации специальных функций правоохранительных органов.

Во-первых, это нормы, регулирующие особые процедуры отбора на правоохранительную службу.

Так, граждане, поступающие на службу в органы наркоконтроля, проходят в порядке, устанавливаемом директором ФСКН России, психологические, психофизиологические и химико-токсикологические исследования, а также тестирование в целях выявления лиц с нервно-психической неустойчивостью, склонностью к злоупотреблению спиртными напитками, употреблению не в медицинских целях наркотических средств, психотропных веществ или их аналогов ${ }^{20}$.

Во-вторых, это нормы, устанавливающие возможность привлечения сотрудников к выполнению специальных заданий.

Например, порядок привлечения сотрудников таможенных органов к выполнению специальных заданий по выявлению, предупреждению и пресечению контрабанды и иных правонарушений в сфере таможенного дела, а также особенности выполнения указанных специальных заданий сотрудниками таможенных органов определяются руководителем Федеральной таможенной службы ${ }^{21}$. Порядок привлечения сотрудников для выполнения специальных заданий по выявлению, предупреждению и пресечению преступлений, отнесенных законодательством РФ к подследственности органов наркоконтроля в сфере оборота наркотических средств, психотропных веществ и их прекурсоров, определяется директором ФСКН России 22 .

\footnotetext{
19 Федеральныйзаконот 27.07.2004№79-Ф3““Огосударственной гражданской службе Российской Федерации” // СЗ РФ. 02.08.2004. - № 31. - Ст. 3215.

20 Пункт 16 Указа о службе в органах наркоконтроля.

21 Статья 21 Закона о службе в таможенных органах.

22 Пункт 73 Указа о службе в органах наркоконтроля.
} 
В-третьих, не могут быть унифицированы нормы, определяющие службу в режимах прикомандирования к иным органам или службы за штатом.

Например, сотрудники органов нарконтроля могут проходить службу не на должностях в ФСКН России и ее территориальных органах в случае нахождения в распоряжении органов наркоконтроля; нахождения за штатом; прикомандирования к федеральным органам государственной власти, органам государственной власти субъектов РФи и организациям ${ }^{23}$. Возможности таких специальных режимов службы допускаются в органах внутренних дел и в таможенных органах.

В-четвертых, это нормы, предусматривающие специальные гарантии личной безопасности.

Такие нормы установлены, например, для сотрудников уголовно-исполнительной системы и членов их семей (специальный порядок предоставление сведений о них, обеспечение оружием и специальными средствами индивидуальной защиты для постоянного ношения и хранения, применение физической силы и спецсредств на охраняемых объектах, прохождение специальной подготовки и периодической проверки на пригодность к действиям в условиях, связанных с применением физической силы, специальных средств и оружия, а также на умение оказывать первую помощь пострадавшим ${ }^{24}$.

В-пятых, это нормы, регулирующие применение внешних атрибутов (формы, нагрудных знаков, знаков отличия, служебных удостоверений) и устанавливающие текст присяги, поскольку в данном тексте отражаются целевые установки, отражающие особое функциональное назначение сотрудников того или иного правоохранительного органа.

Исследование вопросов и объектов унификации норм, регулирующих порядок прохождения службы в правоохранительных органах, являющихся федеральными органами исполнительной власти, и исключений из такой унификации, позволяет сформулировать следующие выводы.

В законодательстве, регулирующем порядок прохождения правоохранительной службы, больше общего, чем специального. Процесс унификации этого законодательства уже имеет место за счет распространения норм Закона о службе в органах внутренних дел на другие правоохранительные органы. Развитие дан- ного процесса видится в продолжении унификации норм, регулирующих порядок прохождения правоохранительной службы, в первую очередь, в таможенных органах и органах наркоконтроля.

Однако такая унификация должна осуществляться не за счет распространения норм закона о правоохранительной службе на данные органы, а за счет рационального определения масштаба, способа и основ унификации. Как отмечалось выше, ряд норм Закона о службе в органах внутренних дел менее удачен, чем, например, нормы Закона о службе в таможенных органах (вопросы определения функций кадровых служб, основания дисциплинарной ответственности, результаты аттестации, и др.), хотя по времени Закон о службе в таможенных органах был принят намного раньше.

В процессе унификации следует выделять те правоотношения, которые должным образом не урегулированы ни в одном из анализируемых выше законов, - это, например, нормы, определяющие требования к должностному регламенту. Структура должностного регламента и требования к нему должны быть идентичны для всех правоохранительных органов, поскольку должностной регламент имеет определяющее значение для обеспечения эффективного исполнения служебных обязанностей.

Определение исключений из процесса унификации не менее значимо, чем объектов унификации. Важно определение не только этих норм, но и вида нормативного акта (нормативных актов), которым они будут закреплены, и его юридической связи с законом о правоохранительной службе, который будет являться итогом унификации законодательства о прохождении правоохранительной службы.

Для закрепления особенностей прохождения правоохранительной службы, унификация которых нецелесообразна, наиболее рационален такой вариант - можно посвятить соответствующим нормам отдельную главу или раздел закона о правоохранительной службе. Отдельные ведомственные нормативные акты принимать не следует, поскольку это может снизить эффективность реализации принципа законности правоохранительной службы и создать риск лоббирования ведомственных интересов в подзаконных актах.

23 Пункт 4 Указа о службе в органах наркоконтроля.

24 Статья 33 Закона РФ от 21.07.1993 № 5473-1 «Об учреждениях и органах, исполняющих уголовные наказания в виде лишения свободы» // Ведомости СНД и ВС РФ». 19.08.1993. № 33. Ст. 1316 (далее - Закон о службе в ФСИН). 


\section{Библиографический список:}

1. Административное право: учебник / под ред. Л.Л. Попова, М.С. Студеникиной. - М.: Норма, 2008. - 992 с.

2. Артемьев А.М. Государственная правоохранительная служба: системные свойства, функции, правовое обеспечение: автореф. дис. на соиск. уч. ст. ... д-ра юрид. наук. - М., 2008. - 23 с.

3. Бакун В.М. Административно-правовой статус служащих правоохранительной службы: автореф. дис. на соиск. уч. ст. ... канд. юрид. наук. - М., 2006. - 25 с.

4. Бельский К.С. Полицейское право. Лекционный курс / под ред. канд. юрид. наук А.В. Куракина. - М.: Изд-во «Дело и сервис», 2004. - 816 с.

5. Гулягин А.Ю. Правоохранительная система: обусловленность законностью // «Российский следователь». 2012. - № 9.

6. Караваев А.Н. Поощрение в системе правоохранительной службы: автореф. дис. на соиск. уч. ст. ... канд. юрид. наук. - Саратов, 2005. - 24 с.

7. Овсянко Д.М. Государственная служба Российской Федерации: учеб. пособие. - М.: Юристь, 2008. - 447 с.

8. Павленко К.А. Служебная дисциплина в системе правоохранительной службы Российской Федерации: автореф. дис. на соиск. уч. ст. ... канд. юрид. наук. - Воронеж, 2011. - 24 с.

9. Погребежский К.А. Правовое обеспечение государственной правоохранительной службы и пути его совершенствования: автореф. дис. на соиск. уч. ст. ... канд. юрид. наук. - М., 2010. - 26 с.

10. Пролетенкова С.Е. Особенности реализации конституционных прав свободы совести и свободы вероисповедания военнослужащими, сотрудниками ОВД и иных правоохранительных органов: автореф. дис. ... на соиск. уч. ст. канд. юрид. наук. - СПб., 2005. - 21 с.

11. Степаненко Ю.В. Правоохранительная деятельность: эволюция теоретических взглядов // Административное право и процесс. - 2013. - № 1.

\section{References (transliteration):}

1. Administrativnoe pravo: uchebnik / pod red. L.L. Popova, M.S. Studenikinoi. - M.: Norma, 2008. - 992 s.

2. Artem'ev A.M. Gosudarstvennaya pravoohranitel'naya sluzhba: sistemnye svoistva, funkcii, pravovoe obespechenie: avtoref. dis. na soisk. uch. st. ... d-ra yurid. nauk. - M., 2008. $-23 \mathrm{~s}$.

3. Bakun V.M. Administrativno-pravovoi status sluzhashih pravoohranitel'noi sluzhby: avtoref. dis. na soisk. uch. st. ... kand. yurid. nauk. - M., 2006. $-25 \mathrm{~s}$.

4. Bel'skii K.S. Policeiskoe pravo. Lekcionnyi kurs / pod red. kand. yurid. nauk A.V.Kurakina. - M.: Izd-vo «Delo i servis», 2004. $-816 \mathrm{~s}$.

5. Gulyagin A.Yu. Pravoohranitel'naya sistema: obuslovlennost' zakonnost'yu // "Rossiiskii sledovatel'”. — 2012. — № 9.

6. Karavaev A.N. Pooshrenie v sisteme pravoohranitel'noi sluzhby: avtoref. dis. na soisk. uch. st. ... kand. yurid. nauk. Saratov, 2005. $-24 \mathrm{~s}$.

7. Ovsyanko D.M. Gosudarstvennaya sluzhba Rossiiskoi Federacii: ucheb. posobie. - M.: Yurist', 2008. - 447 s.

8. Pavlenko K.A. Sluzhebnaya disciplina v sisteme pravoohranitel'noi sluzhby Rossiiskoi Federacii: avtoref. dis. na soisk. uch. st. ... kand. yurid. nauk. - Voronezh, 2011. - 24 s.

9. Pogrebezhskii K.A. Pravovoe obespechenie gosudarstvennoi pravoohranitel'noi sluzhby i puti ego sovershenstvovaniya:avtoref. dis. na soisk. uch. st. ... kand. yurid. nauk. - M., 2010. $-26 \mathrm{~s}$.

10. Proletenkova S.E. Osobennosti realizacii konstitucionnyh prav svobody sovesti i svobody veroispovedaniya voennosluzhashimi, sotrudnikami OVD i inyh pravoohranitel'nyh organov: avtoref. dis. ... na soisk. uch. st. kand. yurid. nauk. - SPb., 2005. - $21 \mathrm{~s}$.

11. Stepanenko Yu.V. Pravoohranitel'naya deyatel'nost': evolyuciya teoreticheskih vzglyadov // Administrativnoe pravo i process. - 2013. - № 1. 